\title{
On Over-compensation and Principles of Linguistic Humor E-C Translation
}

\author{
Qian Han \\ Dalian University of Technology, Dalian, China \\ Email: hanqian74@sina.com
}

\begin{abstract}
Skopos theory and Translation Variation Theory have entitled Chinese translators to deal with linguistic humor translation in a broader framework and approach it with compensation translation. However, some translators' views exceed the limits and over-compensation happens, leading to a new serious problem. Therefore, this paper puts forward two principles about linguistic humor translation to prevent translation from turning into creation.
\end{abstract}

Index Terms - over-compensation, principle, creation

\section{INTRODUCTION}

English linguistic humor is the rhetoric device-dependent humor. It makes best use of homophonic words or phrases, polyphones, polysemants, homographs, perfect homonyms and full homonyms to create pun, zeugma, malapropism, mondegreen, hypallage, parody, spoonerism and so on in order to achieve humorous effect. Linguistic features in English linguistic humor are thought to be impossible to be duplicated in Chinese because English and Chinese belong to different language families. For example, "Better late than the late". Besides being an imitation of the well-known western saying "Better late than never", this joke also contains a polysemant "late", which means both "not on time" and "someone who is dead". The phonetic feature coupled with semantic ones causes great difficulties for translators.

With the change of people's translation ideology and the emergence of new theories, Chinese researchers have succeeded in putting forward some new methods, such as compensation translation, to translate English linguistic humor. However, over-compensation happens too and leads to new problems. The solution to this new problem is badly needed now.

\section{TRANSLATABILITY OF LINGUISTIC HUMOR IN UNTRANSLATABILITY}

This is an era when new theories keep emerging, so linguistic humor translation is put into a broader framework now and its criteria have been re-oriented. Skopos theory by Christiane Nord and Translation Variation Theory by Chinese researcher Huang Zhonglian give us strong theoretical support to deal with the issue from new aspects. Skopos theory views translation from a more functional and sociocultural oriented approach. It stresses the purpose of translation and allows the possibility of the same source text being translated in different ways. Translation Variation Theory legalizes translation variants, stating that complete translation is not the exclusive part of translation; translation variants and shifting devices like rewriting are integral components as well.

In addition to the new theories, inspirational thinking makes its contributions to linguistic humor E-C translation,too. Translators can refine their knowledge and experience by keeping an observant eye on bilingual and bi-dialectal renderings that take place in their daily life and remaining alert to naming and renaming practices in intra-lingual and inter-lingual communications. Creative mind converts the "untranslatable" into "translatable".

So English linguistic humor becomes accessible in some sense by compensation translation.

To make a clear classification of compensation is as hard as to give a comprehensive definition. It is classified into compensation in kind, compensation in place, compensation by merging and compensation by splitting by Hervey \& Higgins and parallel compensation, contiguous compensation and displaced compensation by Harver(Chen, 2007); explicit compensation and implicit compensation by Ma Hongjun (Ma, 2003) and compensation by integration, compensation by isolation, compensation with the same device, compensation with a different device, compensation in a parallel location and compensation in a displaced location, synchronous compensation and compensation in difference by Xia Tingde(Xia, 2006). This paper classifies compensation into three main categories: compensation for the phonological loss, compensation for the semantic loss and compensation for the syntactic loss. Under these three categories are four strategies: annotation, substitution, recontextualization and splitting.

\section{A. Annotation}

Annotation in linguistic humor translation usually takes the form of literal translation with footnotes or endnotes, which is meant to introduce the relevant knowledge of the source text (i.e. ST) to the target text (i.e. TT) readers so that 
the TT readers can sense the humor. For example: A dead leaf fell in Soapy's lap. That was Jack Frost's card. (from The Cop and the Anthem by $O$ Henry)

Translation: 一片枯叶飘落到苏贝的膝头。那是杰克·弗罗斯特的名片。

译注：杰克·弗罗斯特，原文是 Jack Frost,是英文里对“寒霜”的拟人称呼。

Any native speaker will easily feel the sense of humor the moment he comes to the part of "Jack Frost's card", because "frost", the ice crystals covering the ground when the temperature outside falls below freezing point, is converted into "Frost", a person's surname. But to gain the same humorous effect in the Chinese translation, it is far more than the matter of a slight change from the small letter " $\mathrm{f}$ " into the big one, because Chinese is not an alphabetic language. If the translator simply uses transliteration and translate "Frost" as a person's name, he would get the version “杰克·弗罗斯特” and definitely lose the connotative meaning of the word. But if he gives priority to the implied meaning (i.e. being cold), he would be criticized as unfaithful to the original. So annotation is a compromise in this situation.

\section{B. Substitution}

This method is especially effective in dealing with pun in English linguistic humor. When proper names, culture-loaded terms or wordplay cannot be literally translated into the target language, translators often replace these elements with functionally equivalent ones. Although replacement destroys the linguistic properties of the original, it can preserve the contextual effects quite well and sometimes can make up for the lost beauty. It is the optimum seeking-method to effectively improve the readability of translation. For example: Better late than the late. The word "late" has two meanings: "not on time for something" and "someone who is dead". So the rhetorical device in the ST is antalaclasis. We cannot find a Chinese polysemant that happens to have the same meaning as the word "late". So the translator forms a paronomasia, 晚了总比完了好, with the similar pronunciation in it, which functions well in bringing the same humorous effect to the readers of the TT.

\section{Recontextualization}

Recontextualization applies to the situation that an original context (including features of the language) may play such an essential part in the perlocution that no degree of exegesis or marking combined will achieve the desired effects (Hickey, 2001). For example: Romeo: What have thou found? Mercutio: No hare, sir.

The cultural background knowledge enables the ST readers to sense the humor embodied in the word "hare", because the image of a hare reminds them of a prostitute. But when "hare" is translated into Chinese “野兔” as it means, it will lose the cultural connotation and bring no humorous effect among the TT readers at all. So the translator borrows a new image in Chinese culture "野鸡”, which has the same connotative meaning to the Chinese people as "hare" to those who speak English and translate the humor into 罗:你发现了什么? 墨:倒不是野鸡(妓). The part of the context is reset in the translation, but the meaning of the ST is loyally conveyed into Chinese without any loss of humorous flavor.

\section{Splitting}

Splitting can be applied when two meanings are embodied in one sentence. For example: A: What do lawyers do when they die? B: Lie still.

The humorous effect is in the sentence "Lie still" that has two meanings, "to lie there quietly" and "still telling something untrue". The translator splits these two meanings and translates them both into Chinese. The translation goes like this: 律师死了干啥?身子动弹不得, 嘴上撒谎依旧.

It is easily seen from the above examples that compensation translation can work well if used in the right way. It serves as the best possible solution to the linguistic humor translation.

\section{OVER-COMPENSATION AND PRINCIPLES OF LINGUISTIC HUMOR E-C TRANSLATION}

It's comforting to see that we have found new approaches to deal with linguistic humor E-C translation, but some translators' views exceed the limits, so there is a tendency that translation is turning into creation, which changes the essential attribute of translation and leads to self-denial (Zhao, 2005). Does the multiplicity of criteria lead to the result of no criteria? Is it true that the end justify the means? The answer is that there are always principles we should abide by to keep the balance between translation and creation.

Xia Tingde(2006) summarizes six principles of descriptive nature about compensation: principle of demand; principle of relation; principle of focus; principle of minimal distance; principle of the same function and principle of consistency. But these six principles are too general in the case of linguistic humor translation. Based on the Skopos theory and Translation Variation Theory, two principles are put forward in this paper, which are meant to prevent over-compensation from happening.

\section{A. Principle of Necessity}

"The basic principle of Skopos theory is 'The translation method is determined by the purpose of the target text'. This might be understood as 'The end justifies the means' and translators might want to override the source-text 
author's communicative intentions just to achieve the purpose defined by the client or to please the target audience. But translators are responsible for the effects their work may have for either the target audience or the source-text author or the client or even the translator as an individual."(Bian, 2006, p,45) This responsibility is what she calls "loyalty". It is an ethical concept limiting the otherwise unlimited range of possible purposes. So the first principle translators should keep in mind while doing linguistic humor English-Chinese translation is Principle of Necessity.

Principle of Necessity means translators shouldn't employ compensation strategies except on the occasion when there is no other way. Linguistic features block the way of using common translation methods so compensation is required. But compensation is needed only when it is necessary. The abuse of it only leads to wrong translation.

Let's study the translation of a dialogue in the movie Jurassic Park, which took place between a reptile expert and a little naïve boy who associated a blind dinosaur with a blind person and thought that the blind dinosaur must have a dog as the blind person has a guiding dog. The original transcript reads like this:

"What do you call a blind dinosaur?"

"I don't know. What do you call it?"

"What do you call a blind dinosaur's dog?"

"You got me."

The dialog is translated into:

“请问黑色的恐龙叫什么龙? ”

“乌龙。”

“请问最有钱的恐龙叫什么龙? ”

“猪笼（龙）”

This translation is taken as a good example of adaptation strategy by some researchers, who think that it brings the humor to the audience by domesticating the language and cultural associations (Qin, 2007). However, when reexamined carefully, its mistake is right there — it violates the Principle of Necessity by using compensative solution when unnecessary. Adaptation proves useful in solving the problem, but if handled at will without any restriction it is no good at all.

In the above example the conversation sounds funny not because of the language the little boy used but because of the way he thought. He believed a blind dinosaur should have a dog guiding its way like a human being does. So he asked the scientist the second question how he called a blind dinosaur's dog after the first question about how to call a blind dinosaur. In the translation the translator changed the whole context in order to bring laughter, failing to realizing the same humorous effect can be easily achieved by using the same rhetorical device used in the ST instead of appealing to compensation translation. A modified translation goes like this:

“您怎么称呼一只盲龙啊?”

“不知道。你叫它什么?”

“那您又怎么称呼盲龙的狗呢?”

“你可难倒我了! ”

“A blind dragon” is translated into “盲龙”, the mimic form of “盲人”. By doing this, the author successfully keeps the translation loyal to the ST both in the terms of content and the humorous effect.

\section{B. Principle of Minimum Compensation}

When compensation is the only way to translate a humorous English text, the principle is that the fewer of compensated places there are and the fewer of compensation strategies we use, the better the translation would be. This is Principle of Minimum Compensation.

Translation criteria are growing multiple but it does not mean there shall be no criterion. It means we should tolerate the existence of many criteria and accept those reasonable ones. There is always a lowest level or the bottom line for translation practice to prevent the production of unqualified translations (Gao, 2007). Prof. Yang Zijian (2002) believes all the translations between the translation and creation make a set. The representation formula is like this: $\mathrm{T}=\left\{\mathrm{t}_{1}, \mathrm{t}_{2}\right.$, $\left.\mathrm{t}_{3} \ldots \mathrm{t}_{\mathrm{n}}\right\} \mathrm{W},(\mathrm{T}=$ translation, $\mathrm{W}=$ write $) . \mathrm{T}_{1}$ is the closest to the original and $\mathrm{T}_{\mathrm{n}}$ is the closest to creation. It is rather difficult to locate the point where the translation ends and creation begins, however, where $\mathrm{T}_{1}$ is is comparatively easier to be determined. So Principle of Minimum Compensation is both quite important and feasible. The analysis of the following translation is an illustration of how this principle will work.

The source text is: "When are you going to fix that front fence, Hiram?"asked the farmer's wife. "Oh, next week when Silas comes home from college." "But what will the boy know about fixing a fence, Hiram?" "He ought to know a heap. He wrote me that he'd been taking fencing lessons for a month."

"Fence" is the barrier between two areas of land while "fencing" is a sport in which two competitors fight each other using very thin sword. The phonetic connection between these two words creates humor in the ST and set a big obstacle for the translators.

A translation is like this:“海拉姆, 你什么时候把防盗网装上? ”妻子问丈夫。“哦, 下个星期吧。西拉斯从学 校放假回来上。” “一个孩子会上这个吗？”“他懂多了！他不是写信告诉我天天都去上网吗？” 
The translator renders the TT understandable to its Chinese readers by translating the first “fence" into “防盗网” and second "fence" into “上网”. However, he violates the Principle of Minimum Compensation. The centermost part of humor in the ST is about two tings/activities — fence(in Chinese it means “围栏”) and fencing (in Chinese it means “击 剑”), but the translator makes both of them disappear in the translation by translating them into other meanings, simply for the purpose of keeping the Chinese translations of these two words sharing one same Chinese character " $\times x$ " so that they will be in correspondence with each other at the phonological level (i.e. $\times \times \times \times$ 网 and $\times \times \times \times$ ). In fact, the translator overdoes the compensation. The humorous effect is likely to be kept the same in the TT even when the original context is remained intact: “海拉姆, 你什么时候把房前的栅栏栏好? ”妻子问丈夫。“哦, 下个星期吧, 等西拉斯从学校 回来。”“一个孩子会栏什么? ”“他懂多了! 他写信告诉他们学跨栏都栏了一个月啦。” This is how Principle of Minimum Compensation functions. In the new translation, the meaning of the first "fence" is unchanged so recontextualization is done at the minimum degree.

Principle of Minimum Compensation also means that translators should respect the underlying formula in the SS and give priority to the rhetorical device(s) that is/are the same to the one(s) used in the source text if several rhetorical devices are available in translating process. In this sense, Principle of Minimum Compensation can also be named as Principle of Same Category Priority. Here is an example. The source text is: The professor rapped on his desk and shouted: "Gentleman, order!"The entire class yelled, "Beer!"

Translation 1:教授拍着桌子喊到: “你们这些年轻人吆喝 (要喝) 什么?”全班学生喊到: “啤酒!”

Translation 2: 教授在讲台上“笃笃笃”敲了几下喊道:“先生们, 请安静! 一 你们叫什么! ?”全班学生齐声蜳道:“啤 酒!”

Translation 3:教授在讲台上“笃笃笃”敲了几下喊道:“同学们!安静一 (一个嗝) 一点吧!”全班学生齐声謽道:“啤 酒!”

An asteismus pun, a pun at the semantic level, is used in the source text to generate humor. The students misinterpret the word "order" deliberately to mess up the class, for "order" can either be used to tell people to stop causing a disturbance or be used by waiters/waitresses in restaurants to their customers to inquire what food they request. Two meanings are interwoven in a single word, which forms insurmountable difficulty in translation.

All the above three translations are successful in terms of transferring the pun from English to Chinese, but it is quite obvious that different rhetorical devices are used. Translation 1 replaces asteismus pun with paronomasia, a phonological pun. Translation 2 and 3 keep the humor at the semantic level, but neither of them keeps the whole underlying formula of the ST because Translation 2 adopts the splitting strategy and Translation 3 uses recontextualization.

Actually, we can easily get a better translation by simplifying Translations 2 into “...先生们, 你们 叫什么!”. The Chinese word " hand, “叫” means "yell 襄”; on the other hand, “叫什么" has the meaning of "what do you want to eat?". So translation keeps the underlying formula of the ST.

\section{CONCLUSION}

Translation of linguistic humor is an art that requires the inspirational thinking. It seems that all the solutions to those so called "untranslatable" are the results of a sudden enlightenment after much brainstorming. However, the inspirational thinking works wonders only occasionally. It is the principle that functions well all the time. So when doing linguistic humor E-C translation, translators should not only make full use of their creative minds but also follow the principles that help them avoid over-compensation.

\section{REFERENCES}

[1] Bian Jianhua. (2006). On-line Discussion with Prof. Christiane Nord on Skopos Theory. Chinese Translators Journal, 1, 44-46.

[2] Chen Lin. (2007). A Comparatively Study on the Compensation in the English Versions of Analects. Master dissertation, East China Normal University.

[3] Gao Yajuan. (2007). A Study on the Indeteerminacy of Translation Thesis and Translation Criteria. Master dissertation, Nanjing Normal University.

[4] Hickey, Leo. (2001). Perlocutionary Equivalence: Marking, Exegesis and Recontextualization. Shanghai: Shanghai Foreign Language Education Press.

[5] Ma Hongjun. (2003). Compensation in Translating: Its Classification and Application. Foreign Languages and Their Teaching, 10, 37-39.

[6] Qin Li. (2007). E-C Humor Translation from the Perspective of Cultural Differences. Master dissertation, Shanghai Jiao Tong University.

[7] Xia Tingde. (2006). A Study on Translation Compensation. Hubei: Hubei Education Press.

[8] Yang Zijian. (2002). The Growth of Translatology. Qingdao: Qingdao Publishing House.

[9] Zhao Yanchun. (2005). A Reductionist Approach to Translatology. Shanghai: Shanghai Foreign Language Education Press. 
Qian Han was born in Jinzhou, China in 1974. She received her M. A. degree in linguistics from Dalian University of Technology, China in 2008.

She is currently a lecturer in the School of Foreign Languages, Dalian University of Technology, Dalian, China. Her research interests include translation study and FLT. 